Abstracta Iranicanica

Revue bibliographique pour le domaine irano-aryen

Volume 34-35-36 | 2017

Comptes rendus des publications de 2011-2013

\title{
Hagit Torge. Pottery from the Persian and Hellenistic Periods at Horbat Burin (East)
}

\section{Astrid Nunn}

\section{(2) OpenEdition}

1 Journals

\section{Édition électronique}

URL : http://journals.openedition.org/abstractairanica/41631

DOI : 10.4000/abstractairanica.41631

ISSN : 1961-960X

Éditeur :

CNRS (UMR 7528 Mondes iraniens et indiens), Éditions de l'IFRI

Référence électronique

Astrid Nunn, "Hagit Torge. Pottery from the Persian and Hellenistic Periods at Horbat Burin (East)», Abstracta Iranica [En ligne], Volume 34-35-36 | 2017, document 60, mis en ligne le 15 juillet 2016, consulté le 26 septembre 2020. URL : http://journals.openedition.org/abstractairanica/41631 ; DOI : https://doi.org/10.4000/abstractairanica.41631

Ce document a été généré automatiquement le 26 septembre 2020.

Tous droits réservés 


\title{
Hagit Torge. Pottery from the Persian and Hellenistic Periods at Horbat Burin (East)
}

\author{
Astrid Nunn
}

\section{RÉFÉRENCE}

Hagit Torge. « Pottery from the Persian and Hellenistic Periods at Horbat Burin (East) ». 'Atiqot, 70, 2012, p. 82.

1 Ces trois pages sont un résumé de deux articles parus en hébreu dans le même périodique. Ḥorbat Burin est situé dans la partie nord de la plaine de Sharon, non loin d'un croisement de la Via Maris avec la voie est-ouest de Naplouse (Neapolis) à Césarée sur le littoral. Deux secteurs ont été ouverts révélant l'une un four (Area A), l'autre des habitations (Area B). La construction des habitations de la phase la plus ancienne, la phase $\mathrm{V}$, remontent au début de la période hellénistique. Mais sous leur fondation les remblais étaient composés de céramique achéménide.

Ce compte rendu concerne également une autre référence $\left(n^{\circ} 59\right)$ :

3 Uzi 'Ad. « Horbat Burin (East): Remains of Buildings and a Pottery Kiln from the Persian to the Beginning of the Early Islamic Periods ». 'Atiqot, 70, 2012, p. 80-81. 


\section{AUTEURS}

\section{ASTRID NUNN}

Université de Munich 